\title{
The System of Lime, Silica, and Water at $180^{\circ} \mathrm{C}$
}

\author{
Richard B. Peppler
}

\begin{abstract}
Solid-liquid equilibria in the system $\mathrm{CaO}-\mathrm{SiO}_{2}-\mathrm{H}_{2} \mathrm{O}$ were investigated at $180^{\circ} \mathrm{C}$. Only four compounds were found to be stable in equilibrium with the liquid: Xonotlite $(5 \mathrm{CaO}$. $5 \mathrm{SiO}_{2} \cdot \mathrm{H}_{2} \mathrm{O}$, hillebrandite $\left(2 \mathrm{CaO} \cdot \mathrm{SiO}_{2} \cdot \mathrm{H}_{2} \mathrm{O}\right), \alpha$-quartz, and $\mathrm{Ca}(\mathrm{OH})_{2}$. The metastable equilibrium curves of gyrolite $\left(2 \mathrm{CaO} \cdot 3 \mathrm{SiO}_{2} \cdot 2 \mathrm{H}_{2} \mathrm{O}\right)$ and a particular silica gel were determined. The results also suggested several other metastable compounds. Supplementary experiments of six months' duration with oxide mixtures confirmed the stability at $180^{\circ} \mathrm{C}$ of only two ternary compounds, xonotlite and hillebrandite.
\end{abstract}

\section{Introduction}

The system $\mathrm{CaO}-\mathrm{SiO}_{2}-\mathrm{H}_{2} \mathrm{O}$ has been the subject of many investigations. Under hydrothermal conditions, this system yields a number of crystalline compounds [1]. However, only tentative and qualitative compatibility diagrams have been published to date. Most investigators have concerned themselves primarily with the identities of the products obtained. The goal of the present investigation has been not only to identify the products formed, but also to determine the quantitative equilibrium relationships as accurately as possible.

The importance of studies of this system to an understanding of the setting of portland cement, the pozzolanic reaction, and the formation of sand-lime bricks is apparent. The $180^{\circ} \mathrm{C}$ isotherm of this system was chosen for investigation because of its direct applicability to steam-cured portland-cement products.

\section{Apparatus and Procedure}

Stainless-steel autoclaves of $1 / 2^{-}$to 1 -liter capacity were used. These have been described in detail elsewhere [2]. Briefly, each consisted of two similar vessels separated by a filter disk. In each experiment, one vessel was filled with solid and liquid phases in the proportion of $2 \mathrm{~g}$ of solid per liter of liquid, and the autoclave was assembled. It was heated in an electric oven maintained at $180^{\circ} \pm 2^{\circ} \mathrm{C}$ for the desired period of time. When the autoclave was removed, filtration was accomplished by inverting it in cold water and condensing the vapors in the "empty" vessel.

The solid reaction products were washed with alcohol and ether, and dried at $45^{\circ} \mathrm{C}$. Afterward they were examined petrographically and X-ray powder patterns were obtained. In some cases, differential thermal-analysis (DTA) curves and absorption tests with methylene blue were made.

The filtrate was analyzed for lime and silica. The lime was determined gravimetrically by precipitation as the oxalate and ignition to the oxide. Silica was determined gravimetrically except where its concentration was less than $0.01 \mathrm{~g}$ /liter. In such cases, it was determined colorimetrically as the silicomolybdate, using a standard sodium chromate solution as a color reference.
The solutions of $\mathrm{CaO}$ were prepared by igniting reagent quality $\mathrm{CaCO}_{3}$ overnight at $950^{\circ} \mathrm{C}$ and dissolving the resulting $\mathrm{CaO}$ in ordinary distilled water.

A commercial silica gel was used as a source of silica. It was found to contain 0.05 percent of $\mathrm{Na}_{2} \mathrm{O}$ and 0.01 percent of $\mathrm{K}_{2} \mathrm{O}$ and to have an $\mathrm{HF}$ residue of 0.35 percent and an ignition loss at $1,100^{\circ} \mathrm{C}$ of 6.50 percent. An air alutriation stack was used to fractionate some of the gel into two parts, one of particle size above $10 \mu$ and the other below $10 \mu$. It was found that the reactivities of the two fractions were not significantly different at $180^{\circ} \mathrm{C}$; consequently, the unfractionated gel was used throughout this investigation.

In some cases, crystalline calcium hydrosilicates were used as the initial solid phases. The compounds for this purpose were synthesized by hydrothermal treatment of oxide mixtures in a Morey bomb as follows: Gyrolite $\left(2 \mathrm{CaO} \cdot 3 \mathrm{SiO}_{2} \cdot 2 \mathrm{H}_{2} \mathrm{O}\right)$ from a $2: 3$ molar ratio of $\mathrm{CaO}$ to $\mathrm{SiO}_{2}$ at $350^{\circ} \mathrm{C}, 6$ days, 163atm pressure; xonotlite $\left(5 \mathrm{CaO} \cdot 5 \mathrm{SiO}_{2} \cdot \mathrm{H}_{2} \mathrm{O}\right)$ from a 1:1 molar ratio of $\mathrm{CaO}$ to $\mathrm{SiO}_{2}$ at $380^{\circ} \mathrm{C}, 17$ days, 235-atm pressure; and hillebrandite $\left(2 \mathrm{CaO} \cdot \mathrm{SiO}_{2} \cdot \mathrm{H}_{2} \mathrm{O}\right)$ from a 2:1 molar ratio of $\mathrm{CaO}$ to $\mathrm{SiO}_{2}$ at $242^{\circ} \mathrm{C}, 7$ days, 34-atm pressure. Petrographic examination and $\mathrm{X}$-ray diffraction patterns identified the products as the compounds indicated. The experimental conditions for these syntheses were suggested by the work of Flint, McMurdie, and Wells [2].

Metastable solutions were prepared by heating silica gel with a solution of $\mathrm{Ca}(\mathrm{OH})_{2}$ at $90^{\circ} \mathrm{C}$ for 3 weeks, filtering, and mixing the clear filtrate with $\mathrm{Ca}(\mathrm{OH})_{2}$ solutions.

Contamination of the liquid phases by attack on the autoclaves occurred in most experiments. The soluble iron introduced into solution was, however, less than $1 \mathrm{ppm}$. Chromium was a worse offender. As much as $30 \mathrm{ppm}$ as calcium chromate would sometimes be found in the liquid phase. In such cases, chromium was removed as the hydroxide prior to the determination of calcium oxide, and its color after conversion to chromate, was matched with the standard chromate color reference prior to the determination of silica colorimetrically.

The effect of carbon dioxide, as judged by the observed quantity of calcite in the solid phases, was negligible. 


\section{Phase Equilibria at $180^{\circ} \mathrm{C}$}

\subsection{Approach From Undersaturation}

Data pertaining to this phase of the investigation are presented in table 1 , (A). Silica gel was mixed with saturated solutions of lime water in such proportions as to give initial molar ratios of $\mathrm{CaO}$ to $\mathrm{SiO}_{2}$ from 0.00 to 3.00. These mixtures were heated at $180^{\circ} \mathrm{C}$ from 4 to 15 days. The crystalline products were so fine-grained that only an average or a range of indices of refraction could be obtained, as indicated in column 6 . Because of the small differences among the published refractive indices of the calcium hydrosilicates, and the uncertainty that exists in several cases, the data obtained did not suffice to identify the products.

An X-ray powder pattern was obtained for each solid reaction product. The strong family resemblance of the calcium hydrosilicates and the ambi- guity in published patterns of them made identification difficult. In general, the patterns published by Flint and McMurdie [3] and Taylor and Bessey [1] were used as references. However, to decide upon the identity of the principal phases in the reaction products, the patterns of the compounds synthesized at higher temperatures were arbitrarily taken as standard.

In no case was a single pure phase obtained, as judged by the X-ray patterns. One or two principal phases would be indicated, but there would always be a minority of ambiguous lines. The principal compounds are indicated in column 8 (table 1 ). the minor compounds are not indicated. In general, they were compounds having the $\mathrm{CaO}$ to $\mathrm{SiO}_{2}$ ratio that was present in the initial mixture. Thus in experiments 2,3 , and $4\left(\mathrm{CaO} / \mathrm{SiO}_{2}=0.26\right.$ to 0.63$)$, okenite $\left(\mathrm{CaO} \cdot 2 \mathrm{SiO}_{2} \cdot 2 \mathrm{H}_{2} \mathrm{O}\right)$ was indicated; in experiment $5\left(\mathrm{CaO} / \mathrm{SiO}_{2}=0.80\right)$, the compound $4 \mathrm{CaO}$. $5 \mathrm{SiO}_{2} \cdot 5 \mathrm{H}_{2} \mathrm{O}$; in experiment $6 \quad\left(\mathrm{CaO} / \mathrm{SiO}_{2}=1.05\right)$,

TABLE 1. Solubility relationships in the system $\mathrm{CaO}-\mathrm{SiO}_{2}-\mathrm{H}_{2} \mathrm{O}$ at $180^{\circ} \mathrm{C}$

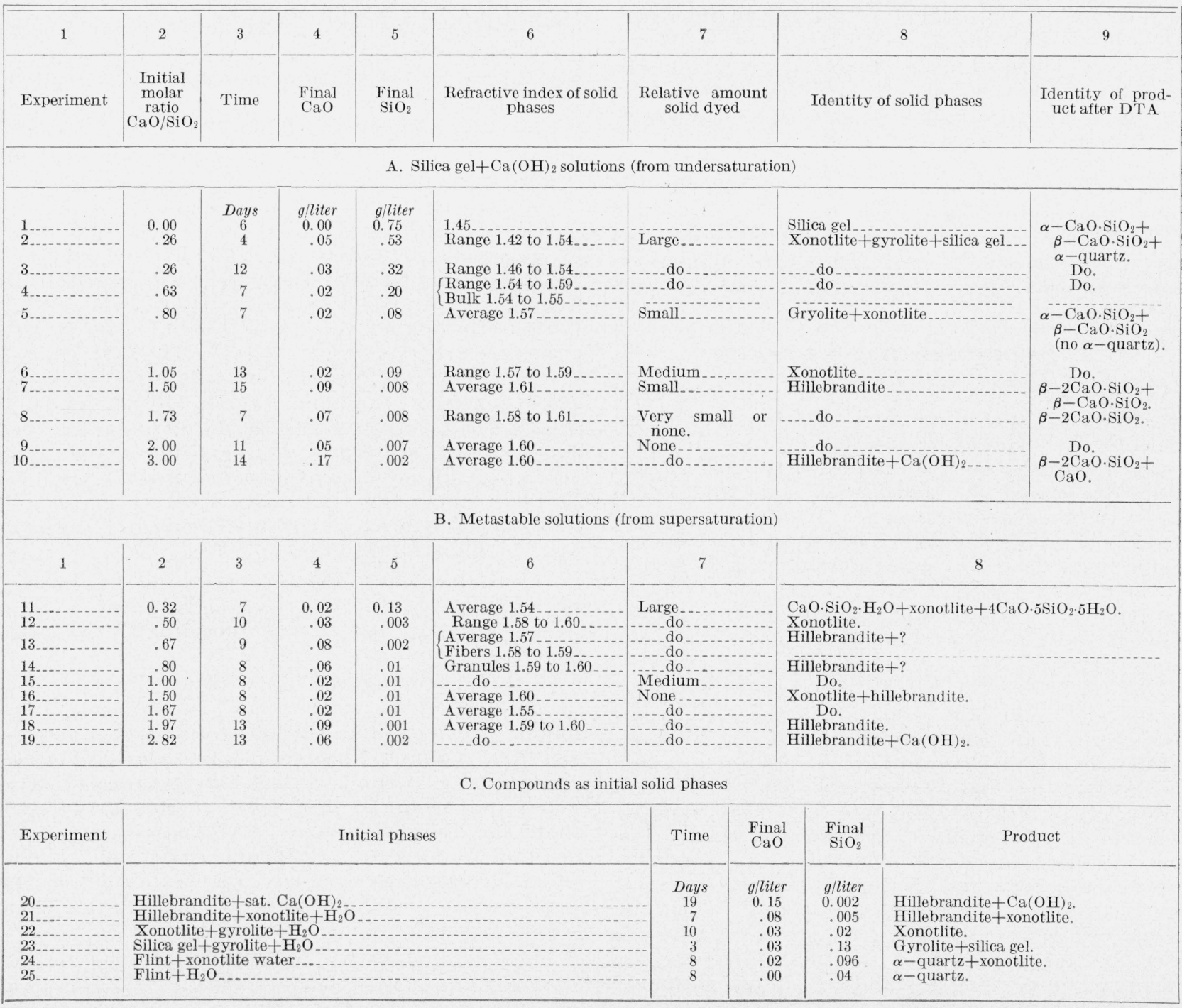


crestmoreite $\left(2 \mathrm{CaO} \cdot 2 \mathrm{SiO}_{2} \cdot \mathrm{H}_{2} \mathrm{O}\right)$ and "CSH I"; in experiment $7\left(\mathrm{CaO} / \mathrm{SiO}_{2}=1.50\right)$, afwillite $(3 \mathrm{CaO}$. $\left.2 \mathrm{SiO}_{2} \cdot 3 \mathrm{H}_{2} \mathrm{O}\right) ; 8\left(\mathrm{CaO} / \mathrm{SiO}_{2}=1.73\right)$, foshagite $(5 \mathrm{CaO}$. $\left.3 \mathrm{SiO}_{2} \cdot 3 \mathrm{H}_{2} \mathrm{O}\right) ; 9\left(\mathrm{CaO} / \mathrm{SiO}_{2}=2.00\right)$, "CSH II"; and $10\left(\mathrm{CaO} / \mathrm{SiO}_{2}=3\right), 3 \mathrm{CaO} \cdot \mathrm{SiO}_{2} \cdot 3 \mathrm{H}_{2} \mathrm{O}$. The lines indicating these compounds were generally weak and constituted less than 10 percent of the number of lines in the pattern.

The solid reaction products were treated with a saturated alcoholic solution of methylene blue hydrochloride for $24 \mathrm{hr}$. washed free of excess dye, and examined microscopically. The relative proportion of dyed particles, indicating unreacted silica gel, is given in column 7 of table 1 . In general, the amount of unreacted silica decreased as the molar ratio of $\mathrm{CaO}$ to $\mathrm{SiO}_{2}$ increased. This is to be expected. The low value in experiment 5 appears to be unusual. It confirms the X-ray and microscopic data, however. Experiment 5 was the first experiment in which no silica gel was observed microscopically in the reaction product.

Differential thermal-analysis (DTA) curves were obtained of the solid reaction products in each case. These are presented in figure 1. The identities of the products after the DTA heat treatment were determined by X-ray powder patterns, and are given in table 1 , (A), column 9.

It is known that the ultimate decomposition products of gyrolite when heated to $1,000^{\circ} \mathrm{C}$ are pseudowollastonite $\left(\alpha-\mathrm{CaO} \cdot \mathrm{SiO}_{2}\right)$ and $\alpha$-quartz, and that those of xonotlite are a mixture of pseudowollastonite and wollastonite $\left(\beta-\mathrm{CaO} \cdot \mathrm{SiO}_{2}\right)$ [4]. The uncombined silica gel in the reaction products evidently transforms to $\alpha$-quartz.

As the molar $\mathrm{CaO}$ to $\mathrm{SiO}_{2}$ ratio increased (experiments 1 to 5), the proportion of wollastonite in the products of DTA heat treatment increased. This indicates that the proportion of xonotlite in the original reaction product had increased. It also confirms the refractive index data (column 6), which indicate that the average index of refraction had increased from that of the unaltered silica gel (1.42) through that of gyrolite (1.54) to that of xonotlite (1.59). The microscopic examinations also showed that gyrolite predominated in experiments 2,3 , and 4 , and xonotlite in experiments 5 and 6 .

The DTA curves, figure 1 , show a family resemblance among the products of experiments 2 to 6 $\left(\mathrm{CaO}\right.$ to $\mathrm{SiO}_{2}$ molar ratios of 0.26 to 1.05$)$. This agrees with the fact that these products are all mixtures of unaltered silica gel, gyrolite, and xonotlite, as indicated by the optical and X-ray data. The endothermic break from $100^{\circ}$ to $300^{\circ} \mathrm{C}$ is evidently the dehydration of the unreacted silica gel. The characteristic exothermic break at $800^{\circ}$ to $850^{\circ} \mathrm{C}$ is evidently associated with the crystallization of wollastonite. The increased size of this break for experiment 3 over that of experiment 2 indicates that the reaction in the autoclave had proceeded further in 12 days than in 4, which agrees with the observation that there was less uncombined silica in the former case. The diminishing size of this break thereafter may possibly be related to the increasing proportion of wollastonite.
It may be observed that the D'TA curves of the products of experiments 7 to 10 also constitute a group, being similar to each other but differing from the first group. The endothermic break for the dehydration of silica gel is absent, correlating with the observation that the amount of silica gel, as determined by dye absorption, was negligible in the corresponding reaction products. The characteristic endothermic break between $500^{\circ}$ and $600^{\circ} \mathrm{C}$ is evidently associated with the dehydration of hille-

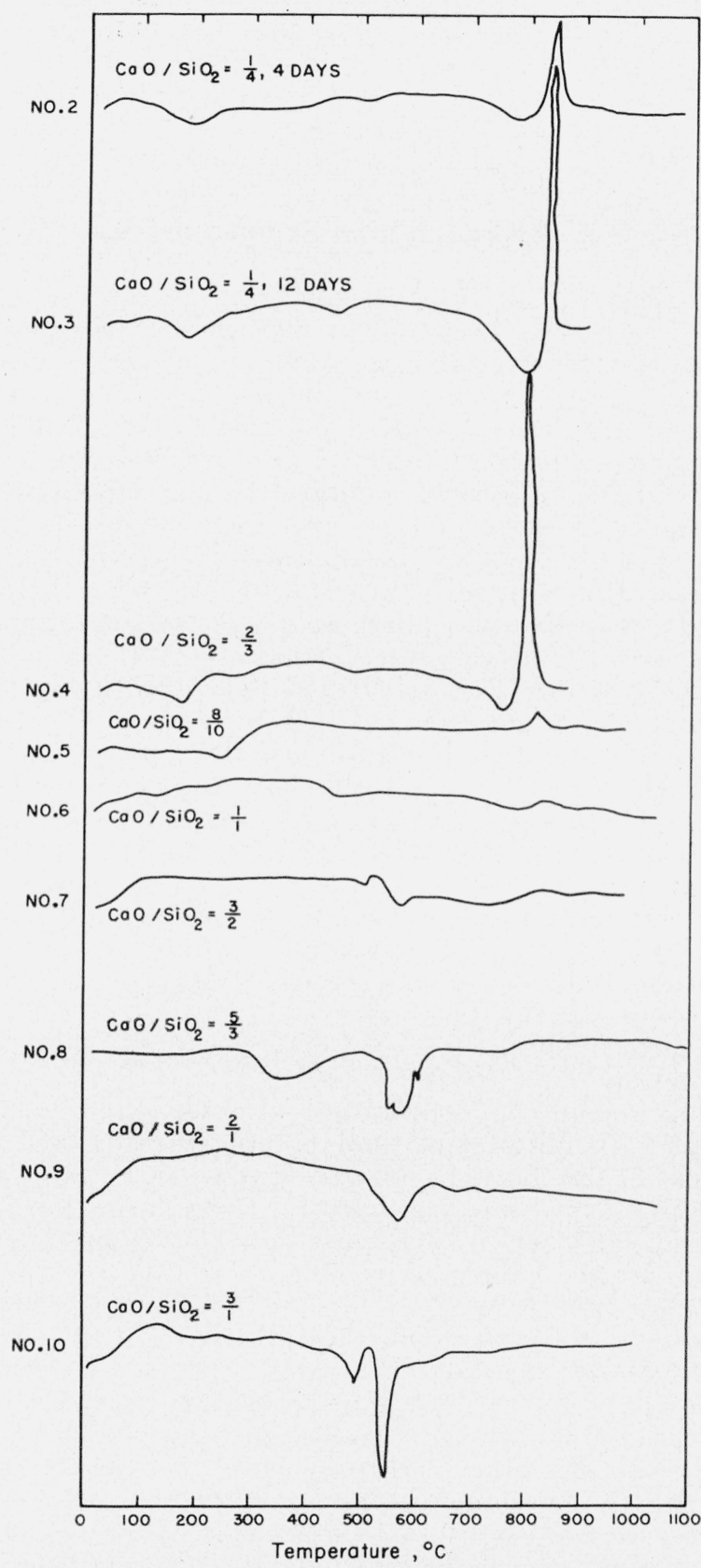

Figure 1. Differential thermal analysis curves of solid reaction products obtained by an approach to equilibrium from undersaturation. 
brandite to $\beta-2 \mathrm{CaO} \cdot \mathrm{SiO}_{2}$. In the case of experiment 10 , the additional endothermic break at $500^{\circ} \mathrm{C}$ is associated with the dehydration of excess $\mathrm{Ca}(\mathrm{OH})_{2}$. The increasing size of the $\beta-2 \mathrm{CaO} \cdot \mathrm{SiO}_{2}$ break with increasing $\mathrm{CaO} / \mathrm{SiO}_{2}$ ratio may possibly be related to an increasing proportion of hillebrandite in the product. The optical and X-ray data also indicated that hillebrandite was the main product in experiments 7 to 10 .

The X-ray pattern of the reaction product of experiment 7 indicated the presence of another hydrosilicate other than hillebrandite. This was confirmed by the presence of a minor amount of wollastonite in the product after D'TA heat treatment. The X-ray patterns of the reaction product of experiment 10 indicated the presence of $\mathrm{Ca}(\mathrm{OH})_{2}$ before and of $\mathrm{CaO}$ after the D'TA heat treatment.

\subsection{Approach from Supersaturation}

A series of metastable solutions of silica gel in lime water was prepared as described in section 2 . These metastable solutions were held at $180^{\circ} \mathrm{C}$ from 7 to 13 days. Data pertaining to this phase of the investigation are presented in table $1,(B)$, and are shown graphically in figure 2 .

Referring to table 1, it may be observed that the products of these precipitation experiments do not have the $\mathrm{CaO}$ to $\mathrm{SiO}_{2}$ molar ratios of the initial mixtures. In the case of experiment 11, the principal products in the solid phase appeared to be a mixture of a very small amount of xonotlite with the compounds $4 \mathrm{CaO} \cdot 5 \mathrm{SiO}_{2} \cdot 5 \mathrm{H}_{2} \mathrm{O}$ and $\mathrm{CaO} \cdot \mathrm{SiO}_{2} \cdot \mathrm{H}_{2} \mathrm{O}$, the former predominating. As these two compounds were not found in the approach from undersaturation, they may be metastable with respect to xonotlite. The observed index, 1.54, coincides with that of $4 \mathrm{CaO} \cdot 5 \mathrm{SiO}_{2} \cdot 5 \mathrm{H}_{2} \mathrm{O}$ [2]. The only other hydrosilicates obtained from supersaturation were xonotlite and hillebrandite, regardless of the initial molar $\mathrm{CaO}$ to $\mathrm{SiO}_{2}$ ratio. Apparently, whatever the immediate products of precipitation may be, they are all metastable with respect to xonotlite and hillebrandite. This is in accord with the results reported in section 3.1 .

The paths of precipitation in these experiments judged by initial and final points are indicated in figure 3. It may be observed that there are two groups of precipitates, namely, those formed when the initial $\mathrm{CaO}$ to $\mathrm{SiO}_{2}$ ratio was less than 1, and those formed when the initial $\mathrm{CaO}$ to $\mathrm{SiO}_{2}$ ratio was greater than 1 . In the former group, the precipitates had a $\mathrm{CaO}$ to $\mathrm{SiO}_{2}$ ratio of from 1 to 2 . The hydrosilicate having this ratio, okenite, was not observed. As no calcium hydrosilicate richer in silica is known, the precipitates must have consisted of silica and other hydrosilicates. In the second group, the precipitates had a $\mathrm{CaO}$ to $\mathrm{SiO}_{2}$ ratio slightly lower than 2 to 1 , indicating the presence of some other phases less rich in lime, in addition to hillebrandite. The path of precipitation of the mixture with a ratio of 2.8 has a slope indicating lime in excess of hillebrandite.

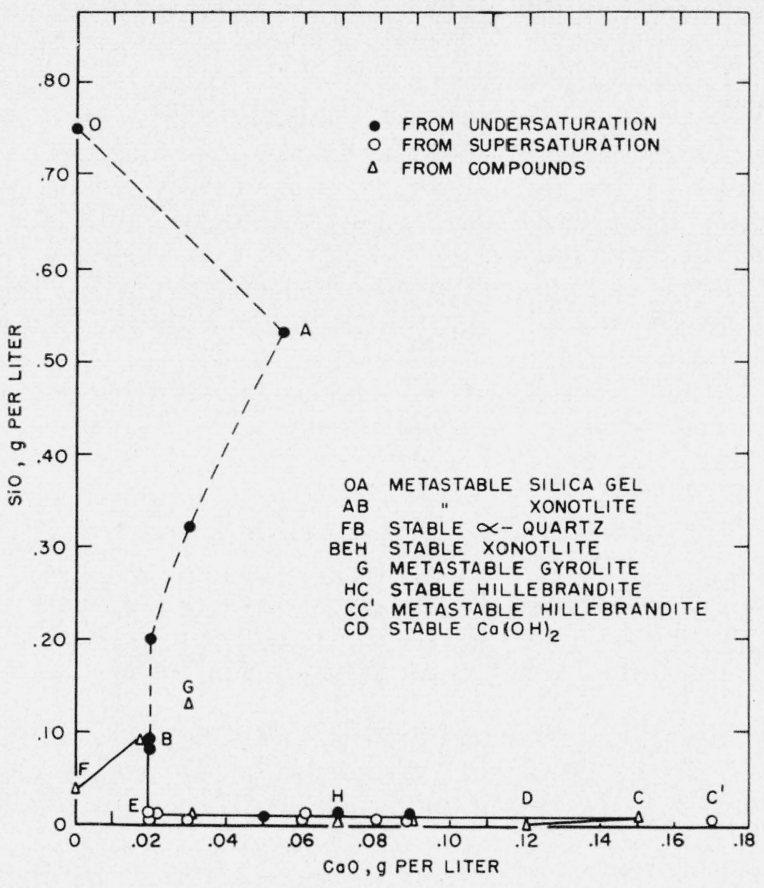

Figure 2. Phase equilibria in the system $\mathrm{CaO}-\mathrm{SiO}_{2}-\mathrm{H}_{2} \mathrm{O}$ at $180^{\circ} \mathrm{C}$.

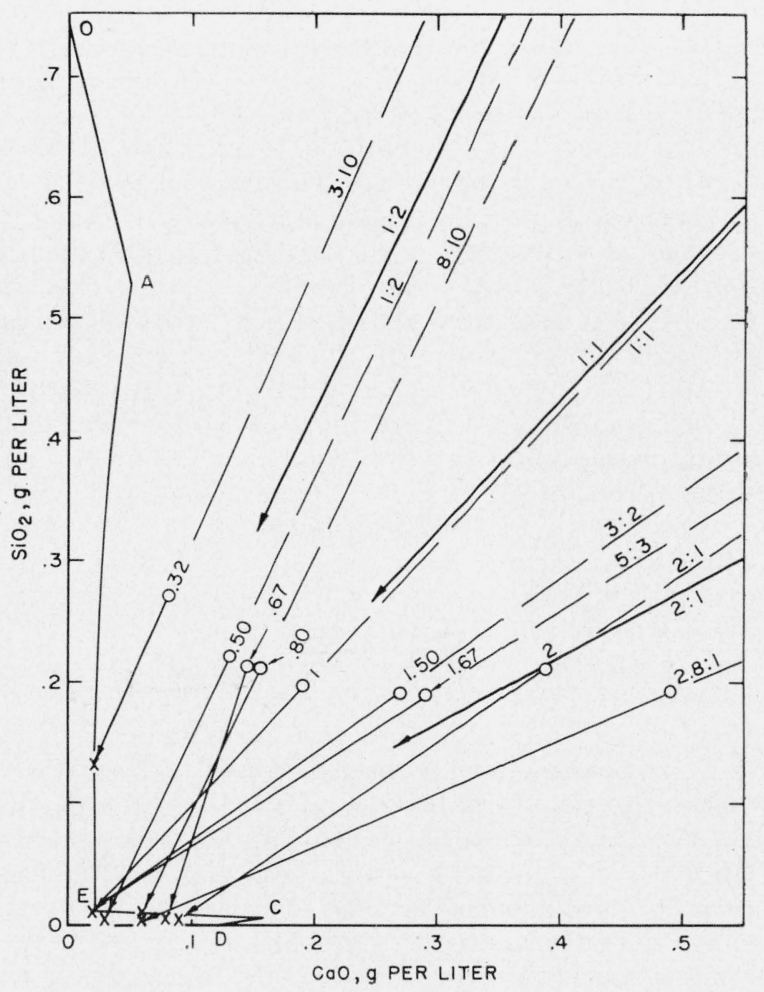

Figure 3. Precipitation from supersaturated solutions in the system $\mathrm{CaO}-\mathrm{SiO}_{2}-\mathrm{H}_{2} \mathrm{O}$ at $180^{\circ} \mathrm{C}$. 
Figure 2 indicates that the data obtained from supersaturation, when plotted, give points falling reasonably well on the solubility curves determined by an approach from undersaturation. The composition of the liquid phase in experiments 15,16 , and 17 (point E) appeared to define the xonotlitehillebrandite invariant point, which the experiments in the preceding section did not; but subsequent experiments indicated this point to represent metastable equilibrium.

The results of dye-absorption tests on the solid reaction products, similar to those described in section 3.1 are shown in column 7. A similar trend of decrease in the uncombined silica is indicated, but the transition to complete combination after 1 to 1 $\mathrm{CaO}$ to $\mathrm{SiO}_{2}$ ratio is sharper.

The compositions of the liquid phases are indicated in columns 4 and 5 of table 1 . The plot of these data in figure 2 indicates that a metastable gyrolitesilica-gel invariant point exists above and to the right of $\mathrm{A}$; that the metastable equilibrium curve for gyrolite lies to the right of $\mathrm{AB}$, which approximates the xonotlite equilibrium curve; and that a stable hillebrandite- $\mathrm{Ca}(\mathrm{OH})_{2}$ invariant point exists at $\mathrm{C}^{\prime}$. Point $\mathrm{D}$ is the solubility of $\mathrm{Ca}(\mathrm{OH})_{2}$ as $\mathrm{CaO}$ in water alone at $180^{\circ} \mathrm{C}$, as taken from a graph of Peppler and Wells [5]. Evidently a xonotlitehillebrandite invariant point must exist between points $\mathrm{A}$ and $\mathrm{C}^{\prime}$ on the curve $\mathrm{AEC}$.

\subsection{Experiments With Compounds}

For this phase of the investigation, hillebrandite, xonotlite, and gyrolite and $\alpha$-quartz were used. A washed flint was used as the $\alpha$-quartz. It was found to have 0.004 percent of $\mathrm{Fe}_{2} \mathrm{O}_{3}$ and an $\mathrm{HF}$ residue of less than 0.02 percent. The $\mathrm{X}$-ray powder pattern showed only $\alpha$-quartz.

The data are presented in table $1,(\mathrm{C})$, and are shown graphically in figure 2. Experiment 20 established the hillebrandite- $\mathrm{Ca}(\mathrm{OH})_{2}$ invariant point, point $\mathrm{C}$, figure 2 , at $0.15 \mathrm{~g}$ /liter of $\mathrm{CaO}$, whereas experiment 10 (table $1, \mathrm{~A}$ ) gave 0.17 . The agreement is reasonable under the circumstances and is further confirmation that hillebrandite is a stable phase in this system at $180^{\circ} \mathrm{C}$.

Experiment 21 was an attempt to establish the hillebrandite-xonotlite invariant point directly. The composition of the liquid phase, point $H$, figure 2 , does not agree with the point $\mathrm{E}$, established by precipitation from supersaturated solutions. Point $\mathrm{H}$ may be considered as the probable xonotlite-hillebrandite invariant point, because it was defined directly from the two compounds. Point E may be a metastable invariant point.

In experiment 22 , a mixture of xonotlite and gyrolite after 10 days gave only xonotlite, confirming the previous conclusion that gyrolite is metastable with respect to xonotlite and silica at $180^{\circ} \mathrm{C}$. In experiment 23 , the gyrolite did not have time to convert to xonotlite. The composition of the liquid phase of this experiment is indicated in figure 2 as point G. It seems probable that an area to the right of $\mathrm{AB}$ represents metastable gyrolite.

Experiment 24 was designed to establish the stable xonotlite- $\alpha$-quartz invariant point.

The solubility of $\alpha$-quartz alone (experiment 6) was found to be $0.04 \mathrm{~g} /$ liter, and a straight line joining point $\mathrm{F}$, representing this composition with the point $B$, is taken as the stable equilibrium curve of $\alpha$-quartz.

\subsection{Experiments With Oxide Mixtures}

Certain experiments of 6 months' duration were undertaken in an attempt to determine beyond any reasonable doubt what compounds are stable in the system $\mathrm{CaO}-\mathrm{SiO}_{2}-\mathrm{H}_{2} \mathrm{O}$ at $180^{\circ} \mathrm{C}$. A series of 10 mixtures of $\mathrm{CaO}$ and silica gel, whose molar $\mathrm{CaO}$ to $\mathrm{SiO}_{2}$ ratio varied from 0.10 to 4.00 , was placed in platinum thimbles, and the thimbles were placed in an autoclave with an excess of water in such a manner that the solid and liquid phases were not in contact. The autoclave was held at $180^{\circ} \mathrm{C}$ for 6 months.

When the products were removed from the autoclave, they were dried for $1 \mathrm{hr}$ at $110^{\circ} \mathrm{C}$ and examined microscopically. The sizes of the crystalline reaction products were so minute that only average indices of refraction could be obtained. It was necessary to resort to X-ray powder patterns to establish their identities. The patterns so obtained were compared with the standard patterns mentioned earlier. The results are presented in table 2 .

Table 2 shows that only two calcium hydrosilicates were obtained, namely, xonotlite and hillebrandite. The unreacted silica gel, indicated as another product in experiments 1,2 , and 3 , was not physically distinct from xonotlite. The xonotlite, rather, was uniformly dispersed in the silica gel, so that the whole mass appeared to be homogeneous and to have a very light grey color between crossed nicols. The X-ray patterns corresponding to these preparations indicated that the gel had partially transformed to $\alpha$-quartz.

In the case of experiments 9 and 10 (table 2), the $\mathrm{Ca}(\mathrm{OH})_{2}$ was physically distinct from the hydrosilicate, and of relatively large particle size. Thus, the appearance of the products obtained after 6 months of hydrothermal treatment was very close to that of the products obtained in a few days when the solid and liquid phases were in contact.

Table 2. Pastes heated at $180^{\circ} \mathrm{C}$ for 6 months

\begin{tabular}{|c|c|c|}
\hline Experiment & $\begin{array}{c}\mathrm{CaO} \text { to } \mathrm{SiO}_{2} \\
\text { ratio }\end{array}$ & Identity by X-ray patterns \\
\hline $\begin{array}{l}1 \\
2 \\
3 \\
4 \\
5 \\
6 \\
7\end{array}$ & $\begin{array}{r}M \\
0.100 \\
.500 \\
.667 \\
.800 \\
1.000 \\
1.500 \\
1.667 \\
2.000 \\
\text { 3. } 000 \\
\text { 4. } 000\end{array}$ & $\begin{array}{l}\text { Xonotlite+silica gel. } \\
\text { Do. } \\
\text { Do. } \\
\text { Xonolite. } \\
\text { Do. } \\
\text { Hillebrandite+xonotlite. } \\
\text { Hillebrandite. } \\
\text { Do. } \\
\text { Hillebrandite+Ca }(\mathrm{OH})_{2} \text {. } \\
\text { Do. }\end{array}$ \\
\hline
\end{tabular}




\section{Discussion}

The $180^{\circ} \mathrm{C}$ isotherm of the system $\mathrm{CaO}-\mathrm{SiO}_{2}-\mathrm{H}_{2} \mathrm{O}$ appears to be more, rather than less, complex than the room temperature isotherm. Although the compounds at $180^{\circ} \mathrm{C}$ are definitely crystalline and give reasonably sharp X-ray patterns, it is difficult to identify them. The number of compounds that can exist metastably in this system appears to be at a maximum at or near $180^{\circ} \mathrm{C}[1,2]$ and would include nearly all the calcium hydrosilicates that have been described. The determination of the phase equilibria of these metastable phases is beyond the scope of the present investigation. Certain conclusions, however, may be drawn.

When the initial $\mathrm{CaO}$ to $\mathrm{SiO}_{2}$ molar ratio is 0.8 or less and silica is initially a solid phase, the two combine to form metastable gyrolite. It transforms then into xonotlite with a rapidity that apparently depends on the $\mathrm{CaO}$ to $\mathrm{SiO}_{2}$ molar ratio, as evidenced by the fact that the proportion of xonotlite increases in the reaction products with increasing $\mathrm{CaO}$ to $\mathrm{SiO}_{2}$ ratio (table $1, \mathrm{~A}$ ). At low $\mathrm{CaO}$ to $\mathrm{SiO}_{2}$ ratio, the transformation is not complete at the end of 12 days (experiment 3). Other phases may first form that are in turn metastable with respect to gyrolite, as indicated by the minority of lines in the powder patterns that match lines of the powder patterns of other compounds more closely. In the presence of excess reactive silica, however, these minor phases apparently exist only transitorily.

When the initial molar $\mathrm{CaO}$ to $\mathrm{SiO}_{2}$ ratio was 1.05 (and silica gel was the solid phase), the only product at the end of 13 days was xonotlite (experiment 6). It is possible that gyrolite first formed and then converted to xonotlite, because a mixture of gyrolite and xonotlite converted in 10 days to xonotlite (experiment 22). This latter experiment establishes conclusively that xonotlite, and not gyrolite, is the stable phase.

Certain analogies can be drawn between the phase equilibria in the system $\mathrm{CaO}-\mathrm{SiO}_{2}-\mathrm{H}_{2} \mathrm{O}$ at room temperature $[4,6]$ and those at $180^{\circ} \mathrm{C}$. At room temperature, available evidence indicates that only two stable ternary compounds, $\mathrm{CSH} \mathrm{I}$ and $\mathrm{C}_{2} \mathrm{SH}$ II, a monocalcium and a dicalcium silicate hydrate, exist. These are analogous, as regards $\mathrm{CaO}$ to $\mathrm{SiO}_{2}$ ratio, to xonotlite and hillebrandite, found to be stable at $180^{\circ} \mathrm{C}$.

At room temperature, the compound $\mathrm{CSH} I$ has been found to vary in $\mathrm{CaO}$ to $\mathrm{SiO}_{2}$ ratio from 0.8 to 1.5 , and the compound $\mathrm{C}_{2} \mathrm{SH}$ II, to vary from 1.4 to 1.9 [7]. In the present study, all compositions from $\mathrm{CaO}$ to $\mathrm{SiO}_{2}$ ratio up to 1.5 gave xonotlite, and higher $\mathrm{CaO}$ to $\mathrm{SiO}_{2}$ ratios gave hillebrandite. The $\mathrm{CaO}$ to $\mathrm{SiO}_{2}$ ratio of the solid reaction products was not determined in this investigation. Kalousek, Logiudice, and Dodson [8]. however, prepared synthetic hillebrandite, as well as the $\alpha$ - and $\gamma$ dicalcium silicate hydrate, in the range $175^{\circ}$ to $250^{\circ}$ $\mathrm{C}$, in which the $\mathrm{CaO}$ to $\mathrm{SiO}_{2}$ molar ratios varied from 1.5 to 2.4 and possibly extended to 3.0 for synthetic hillebrandite ( $\beta$-hydrate). For each hydrate, almost identical X-ray patterns were obtained over the range of varying $\mathrm{CaO}$ to $\mathrm{SiO}_{2}$ ratio. This situation is directly analogous to that found at room temperature, where a varying $\mathrm{CaO}$ to $\mathrm{SiO}_{2}$ ratio, within the limits mentioned above, does not affect the X-ray patterns.

Several previous investigators have prepared dicalcium silicate hydrate $\left(10 \mathrm{CaO} \cdot 5 \mathrm{SiO}_{2} \cdot 6 \mathrm{H}_{2} \mathrm{O}\right)[2,8,9$, $10,11]$, and it has been isolated in steam-cured mortars [12]. This suggests that it might be the stable dicalcium silicate hydrate at $180^{\circ} \mathrm{C}$. The present investigation, however, indicates that hillebrandite is the stable dicalcium silicate hydrate. Kalousek, Logiudice, and Dodson [8] found that the $\alpha$-hydrate, prepared at $175^{\circ} \mathrm{C}$, began to convert to the $\beta$-hydrate (hillebrandite) when the temperature was raised. Their work indicates that many variables, such as type of silica and condition of mixing, helped to determine what hydrate was produced, so that they were not able to assign definite ranges of temperature over which the various hydrates are stable. These same authors found that at $175^{\circ} \mathrm{C}$. when the $\mathrm{CaO}$ to $\mathrm{SiO}_{2}$ ratio fell below 1.8, xonotlite appeared. This is in accord with the results obtained in the present investigation.

Recent work of Heller and Taylor [13] indicates that hillebrandite is the stable dicalcium cilicate hydrate at $180^{\circ} \mathrm{C}$. They found that $\mathrm{Ca}(\mathrm{OH})_{2}$ and silica in $2: 1$ ratio at $180^{\circ} \mathrm{C}$ for 30 days gave hillebrandite. The $\alpha$-hydrate was formed below and the $\gamma$-hydrate above $180^{\circ} \mathrm{C}$. These results were not conclusive, however, because in another experiment they obtained all three hydrates.

The present investigation also is in accord with other recent work of Heller and Taylor [14], which demonstrates that CSH I and afwillite are metastable at $180^{\circ} \mathrm{C}$.

Returning to the group of experiments (table 1, A) where the initial molar $\mathrm{CaO}$ to $\mathrm{SiO}_{2}$ ratio is 1.50 to 3.00 , it is apparent that no stable compound more lime-rich than dicalcium silicate hydrate forms. The hydrate $3 \mathrm{CaO} \cdot \mathrm{SiO}_{2} \cdot 2 \mathrm{H}_{2} \mathrm{O}$ was prepared by Flint, McMurdie, and Wells [2] at and above $200^{\circ} \mathrm{C}$. In experiment 10 , a few weak lines in the X-ray pattern indicated the presence of this hydrosilicate, but they resembled the lines of $\mathrm{Ca}(\mathrm{OH})_{2}$ too closely to prove the existence of the hydrosilicate at $180^{\circ} \mathrm{C}$. The same authors found that $\mathrm{CaO} \cdot \mathrm{SiO}_{2} \cdot \mathrm{H}_{2} \mathrm{O}$ formed at $150^{\circ} \mathrm{C}$ and xonotlite at $175^{\circ} \mathrm{C}$ from a $\mathrm{CaO}$ and $\mathrm{SiO}_{2}$ mixture of 1:1 molar ratio. This would indicate that the compound $\mathrm{CaO} \cdot \mathrm{SiO}_{2} \cdot \mathrm{H}_{2} \mathrm{O}$ is metastable with respect to xonotlite near $180^{\circ} \mathrm{C}$. The results of the present investigation are in accord. However, Flint, McMurdie, and Wells [2] found that the compound $4 \mathrm{CaO} \cdot 5 \mathrm{SiO}_{2} \cdot 5 \mathrm{H}_{2} \mathrm{O}$ formed between $150^{\circ} \mathrm{C}$ [2] and $275^{\circ} \mathrm{C}$ and persisted in this range from 7 to 42 days. This suggests that it is a stable phase at $180^{\circ} \mathrm{C}$, because it was found to transform to xonotlite only at $300^{\circ} \mathrm{C}$. In the present investigation, this compound was found to be metastable with respect to xonotlite at $180^{\circ} \mathrm{C}$. Flint, McMurdie, and Wells used lime-silica gels in their experiments, and these gels were steamed out of contact with the liquid 
phase. Apparently, the rates of reaction of these materials are different, depending on whether they are in contact with the liquid or vapor phase. In the present investigation, for example, the products after hydrothermal treatment of oxide mixtures for 6 months exhibited about the same degree of crystal growth and reaction as had corresponding liquidcontact experiments in 1 to 2 weeks. In the experiments from supersaturation, (table 1, B) the products of experiment 1 were the two compounds mentioned above $\left(4 \mathrm{CaO} \cdot 5 \mathrm{SiO}_{2} \cdot 5 \mathrm{H}_{2} \mathrm{O}\right.$ and $\mathrm{CaO} \cdot-$ $\mathrm{SiO}_{2} \cdot \mathrm{H}_{2} \mathrm{O}$ ) and xonotlite, with respect to which the first two are evidently metastable.

The results of the present investigation are in accord with those of Flint, McMurdie, and Wells [2] as regards the silica-rich compounds. These authors found gyrolite at $150^{\circ}$ to $400^{\circ} \mathrm{C}$ and xonotlite from $175^{\circ}$ to $390^{\circ} \mathrm{C}$, and were unable to prepare okenite in this temperature range.

Several properties of the solid phases of this system used qualitatively in this investigation might, in principle, be used to estimate quantitatively the rate of reaction. These include refractive index, dye absorption. D'TA curves, and X-ray patterns of the products before and after DTA heat treatment.

\section{Summary}

Phase equilibria in the system $\mathrm{CaO}-\mathrm{SiO}_{2}-\mathrm{H}_{2} \mathrm{O}$ were investigated at $180^{\circ} \mathrm{C}$. Only two stable ternary compounds were found, namely, xonotlite and hillebrandite. Two other stable binary compounds found were $\alpha$-quartz and $\mathrm{Ca}(\mathrm{OH})_{2}$. The metastable equilibrium curves of gyrolite and of a silica gel was determined approximately. The results suggested several other metastable compounds. Treating oxide mixtures with $\mathrm{CaO}$ to $\mathrm{SiO}_{2}$ ratios of 0.1 to 4.0 with steam for 6 months at $180^{\circ} \mathrm{C}$ yielded xonotlite and hillebrandite as the only hydrosilicates.

\section{References}

[1] H. F. W. Taylor and G. E. Bessey, A review of hydrothermal reactions in the system $\mathrm{CaO}-\mathrm{SiO}_{2}-\mathrm{H}_{2} \mathrm{O}$, Mag. of Concrete Research $\mathbf{2 , 1 5}$ (July 1950).

[2] E. P. Flint, H. F. McMurdie, and L. S. Wells, Formation of hydrated calcium silicates at elevated temperatures and pressures, J. Research NBS 21, 617 (1938) RP1147.

[3] H. F. MeMurdie and E. P. Flint, X-Ray patterns of hydrated calcium silicates, J. Research NBS 31, 225 (1943) RP1560.

[4] J. D. Bernal and L. Heller, Third International Symposium on the Chemistry of Cement (Cement and Concrete Assoc., London, England, Sept. 1952).

[5] R. B. Peppler and L. S. Wells, The system of lime, alumina, and water from $50^{\circ}$ to $250^{\circ} \mathrm{C}$, J. Research NBS 52, 75 (1954) RP2476.

[6] H. H. Steinour, The system $\mathrm{CaO}-\mathrm{SiO}_{2}-\mathrm{H}_{2} \mathrm{O}$ and the hydration of the calcium silicates (Bul. 18, Portland Cement Assoc.) Chem. Rev. 40, 391 (1947).

[7] H. F. W. Taylor, Hydrated calcium silicates, Pt. I, Compound formation at ordinary temperatures, J. Chem. Soc., 3682 (Dec. 1950).

[8] G. L. Kalousek, J. S. Logiudice, and V. H. Dodson, Studies on the lime-rich crystalline solid phases in the system lime-silica water, J. Am. Ceram. Soc. 37, 7 (Jan. 1954).

[9] V. A. Vigfusson, G. N. Bates, and T. Thorvaldson, Hydrothermal syntheses of calcium hydrosilicates, Can. J. Research 2, 520 (1934).

[10] G. E. Bessey, The calcium aluminate and silicate hydrates, Proc. Symposium on Chem. of Cements, p. 178 (Stockholm, Sweden, 1938).

[11] S. Naqai, Hydrothermale synthesen von calciumsilikaten, Z. anorg. u. allgem. Chem. 206, 177 (1932); 20\%, 321 (1932).

[12] T. Thorvaldson and G. R. Shelton, Steam curing of portland cement mortars, a new crystalline substance, Can. J. Research 1, 148 (1929).

[13] L. Heller and H. F. W. Taylor, Hydrated calcium silicates, Pt. IV, Hydrothermal reactions-lime: silica ratio $2: 1$ and $3: 1$, J. Chem. Soc., 2535 (1952).

[14] L. Heller and H. F. W. Taylor, Hydrated calcium silicates, Pt. II, Hydrothermal reactions-lime: silica ratio 1:1, J. Chem. Soc., 2397 (Sept. 1951).

Washington, December 15, 1954.? 